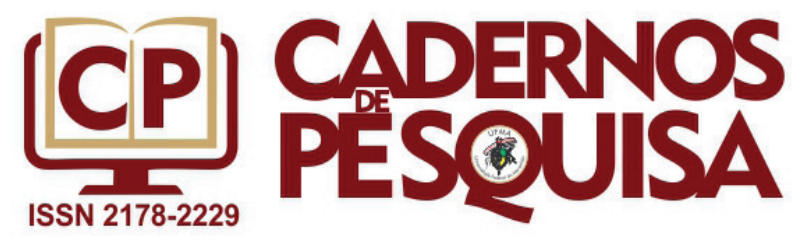

\author{
A INTENSIFICAÇÃO DOS PRINCÍPIOS DO MERCADO NA \\ ORGANIZAÇÃO DAS POLÍTICAS EDUCACIONAIS: \\ ANÁLISE DO CEIPE
}

\author{
THE INTENSIFICATION OF MARKET PRINCIPLES IN THE \\ ORGANIZATION OF EDUCATIONAL POLICIES: \\ ANALYSIS OF CEIPE
}
LA INTENSIFICACIÓN DE LOS PRINCIPIOS DEL MERCADO EN LA ORGANIZACIÓN DE LAS POLÍTICAS EDUCATIVAS: ANÁLISIS DEL CEIPE

Valdelaine Mendes ${ }^{1}$

ORCID:0000-0003-4376-1080

\begin{abstract}
Resumo: Este artigo tem como foco a análise do Centro de Excelência e Inovação em Políticas Educacionais (Ceipe) da Fundação Getúlio Vargas (FGV), criado com o propósito de ser o primeiro think tank especializado em política educacional do Brasil. Interessa aqui discutir quais princípios e valores sustentam as propostas desta organização para a área educacional. Os think tanks atuam para dar o direcionamento das políticas, sem, entretanto, ocupar funções diretamente dentro das secretarias de educação, pois atuam por meio de assessorias, consultorias e parcerias. Ao buscar exercer influência na opinião pública um think tank age como verdadeiro produtor de determinados padrões de inserção na vida social.
\end{abstract}

Palavras-chave: Política educacional. Think Tank. Mercado.

Abstract: This article focuses on the analysis of the Center for Excellence and Innovation in Educational Policies (Ceipe) of the Getulio Vargas Foundation (FGV), created with the purpose of being the first think tank specialized in educational policy in Brazil. It is interesting to discuss what principles and values support this organization's proposals for the educational area. The think tanks act to give direction to the policies, without, however, occupying functions directly within the education departments, as they act through advisory services, consultancies and partnerships. In seeking to exercise influence on public opinion, a think tank acts as a true producer of certain patterns of insertion in social life.

Keywords: Educational policy. Think Tank. Market.

Resumen: Este artículo se centra en el análisis del Centro para la Excelencia e Innovación en Políticas Educativas (Ceipe) de la Fundación Getúlio Vargas (FGV), creado con el propósito de ser el primer grupo de think tank especializado en política educativa en Brasil. Es interesante discutir qué principios y valores apoyan las propuestas de esta organización para el área educativa. Los think tanks actúan para guiar las políticas, sin

1 Universidade Federal de Pelotas (UFPel) - Pelotas, RS. 
embargo, sin ocupar funciones directamente dentro de los departamentos de educación, ya que operan a través de servicios de consultoría, consultoría y asociación. Al tratar de ejercer influencia en la opinión pública, un grupo de think tank actúa como un verdadero productor de ciertos patrones de inserción en la vida social.

Palabras clave: Política educativa. Think Tank Mercado.

\section{A INTENSIFICAÇÃO DOS PRINCÍPIOS DO MERCADO NA ORGANIZAÇÃO DAS POLÍTICAS EDUCACIONAIS: ANÁLISE DO CEIPE}

Este artigo tem como foco a análise do Centro de Excelência e Inovação em Políticas Educacionais (Ceipe) da Fundação Getúlio Vargas (FGV), criado com o propósito de ser o primeiro think tank especializado em política educacional do Brasil. Interessa aqui discutir quais princípios e valores sustentam as propostas desta organização para a área educacional. Para alcançar esse objetivo foram analisados livros, artigos e publicações, listados no site do Ceipe, como produção própria ou em parceria com outras organizações, elaborados para subsidiar as discussões e encaminhamentos de ações na área educacional da instituição.

Carvalho (2015), em estudo sobre a produção acadêmica em política educacional em Portugal, no período de 2000-2012, demonstra que há uma consolidação de um tipo de análise na área cujo foco é a multirregulação dos sistemas educativos, "perspectiva que põe em articulação as dimensões da intervenção da autoridade pública e dos atores sociais em contextos de ação concretos, por oposição a uma perspectiva orientada para uma compreensão das políticas através da análise da intervenção legislativa e doutrinária da autoridade pública" (p. 1033).

No estudo o autor revela a necessidade de considerar, nas análises das políticas, as intervenções produzidas pelos sujeitos que não ocupam posições nos governos, mas que por meio de suas ações intervêm diretamente nos sistemas educativos. Essa participação dos atores não estatais na organização e regulação das políticas tem recebido a atenção dos estudiosos da área. Nessa tendência insere-se este estudo, cujo foco central é identificar como organizações, do tipo think tanks, tem exercido influência na organização dos sistemas educacionais.

\section{OS THINK TANKS E A BUSCA PELA FORMAÇÃO DE CONSENSOS EM ESCALA GLOBAL}

Na segunda década do século XXI, há um aumento significativo no número de think tanks no mundo. São organizações que funcionam como "laboratório de ideias" e têm como função produzir informações sobre temas como: política, economia, ciência, meio ambiente, saúde, educação, entre outros, para influenciar a opinião pública e construir consensos, na definição de estratégias para o enfrentamento de problemas sociais e para a definição de políticas públicas. 
Esse aumento pode ser visualizado em um relatório produzido, anualmente, pela Universidade da Pensilvânia, nos Estados Unidos da América (EUA), que tem como finalidade acompanhar o crescimento dos think tanks e criar um ranking daquelas instituições com maior influência em 81 países. No relatório de 2018, foram contabilizados 8.248 think tanks no mundo. Os EUA são o país com maior número, totalizando 1.872. O relatório divide o globo terrestre em sete regiões.

Tabela 1- Distribuição de think tanks no mundo, em 2018

\begin{tabular}{l|r}
\hline Região & Quantidade \\
\hline América do Norte & 2.058 \\
América do Sul e Central & 1.023 \\
África Subsaariana & 612 \\
Europa & 2.219 \\
Leste e Norte da África & 507 \\
Ásia & 1.829 \\
\hline TOTAL & $\mathbf{8 . 2 4 8}$ \\
\hline
\end{tabular}

Fonte: University of Pennsylvania. Global Go To Think Tank Index Reports, 2018.

A Europa possui o maior número de think tanks, porém é a América do Norte que detém a maior concentração dessas organizações, ainda que a distribuição nessa região não seja equilibrada entre EUA, Canadá e México, que possuem 1.872, 100 e 86 cada um, respectivamente. Na região da América Central e do Sul, o Brasil aparece como o país com o segundo maior número de think tanks, atrás apenas da Argentina, conforme pode ser visto na tabela a seguir:

Tabela 2- Dez países com maior número de think tanks na América Central e do Sul, em 2018

\begin{tabular}{l|r}
\hline País & Quantidade \\
\hline Argentina & 227 \\
Brasil & 103 \\
Bolívia & 66 \\
Chile & 64 \\
Colômbia & 64 \\
Peru & 43 \\
Costa Rica & 42 \\
República Dominicana & 40 \\
Paraguai & 33 \\
Equador & 29 \\
\hline
\end{tabular}

Fonte: University of Pensylvania. Global Go To Think Tank Index Reports, 2018. 
O relatório tem como propósito compreender o papel que os think tanks exercem na elaboração das políticas públicas e sua influência na sociedade civil. Os critérios para o estabelecimento da classificação são capacidade de liderança das equipes, quantidade e qualidade das publicações da instituição, desenvolvimento de parcerias, participação nas redes sociais, entre outros. No relatório de 2018 , várias instituições brasileiras aparecem no "Top Think Tanks in Central and South America", conforme pode ser observado a seguir:

Tabela 3 - Instituições brasileiras no "Top Think Tanks in Central and South America"

\begin{tabular}{l|c}
\hline Instituição & Colocação \\
\hline Fundação Getúlio Vargas & $1^{\circ}$ \\
\hline Centro Brasileiro de Relações Internacionais & $3^{\circ}$ \\
\hline Instituto de Pesquisa Econômica Aplicada & $8^{\circ}$ \\
\hline Fundação Fernando Henrique Cardoso & $13^{\circ}$ \\
\hline Centro Brasileiro de Análise e Planejamento & $17^{\circ}$ \\
\hline BRICS Policy Center & $11^{\circ}$ \\
\hline Núcleo de Estudos da Violência (USP) & $31^{\circ}$ \\
\hline Instituto Millenium & $34^{\circ}$ \\
\hline Faculdade de Direito do Sul de Minas & $54^{\circ}$ \\
\hline Forum Brasileiro de Segurança Pública & $69^{\circ}$ \\
\hline Instituto Liberdade & $73^{\circ}$ \\
\hline Instituto Igarapé & $78^{\circ}$ \\
\hline Federação de Órgãos para Assistência Social e Educacional & $81^{\circ}$ \\
\hline
\end{tabular}

Fonte: University of Pennsylvania. Global Go To Think Index Report, 2018.

No Brasil, a FGV, a Fundação Fernando Henrique Cardoso e o Instituto Millenium são exemplos de organizações que operam com a finalidade de produzir conhecimento para influenciar a definição das políticas públicas. Essa influência ocorre pela difusão de ideias em todos os tipos de meios de comunicação, especialmente, na grande imprensa e nas redes sociais; pela formação de quadros para a ocupação de funções públicas; pela articulação com grupos empresariais para a propagação dos valores do mercado na educação, cultura, economia.

Os think tanks são organizações que conduzem pesquisas independentes, produzem engajamento em temas cruciais e desenvolvem soluções inovadoras para problemas em áreas como economia, tecnologia, políticas públicas e sociais, política externa, políticas estratégicas, políticas de negócios etc. (FGV, 2018)

A FGV, além de se destacar entre os think tanks nacionais, na primeira colocação, aparece como sexta organização mais influente do planeta no referido Relatório da Universidade da Pensilvânia. Trata-se, portanto, de uma instituição reconhecida internacionalmente pelo papel que desempenha no desenho das políticas internas e externas no país. 
No período de 11 a 13 de dezembro de 2019 a FGV, juntamente com a Think Tanks and Civil Societes Program University of Pennsylvania (TTCSP), promoveu, na cidade do Rio de Janeiro, o Global Think Tank Summit 2019. Foi a primeira vez que uma edição do evento ocorreu na América Latina. Com o tema "Managing the Global Turbulence and transitions: the role of think tanks", contou com a participação de mais de 140 participantes, representando 55 países e 94 think tanks. Com o propósito de trabalhar para ouvir, aprender e trocar experiências, vários participantes do evento, afirmaram a importância dos think tanks unirem-se para incentivar soluções para os problemas do planeta e exercer influência na definição das políticas locais e globais. O representante do Instituto Brookings, Michael O'Hansen, destacou a importância do trabalho articulado das organizações de diferentes partes do planeta ${ }^{2}$ na definição das prioridades e diretrizes de ação.

A realização desse evento pela FGV, no Brasil, é revelador do peso que essas organizações têm na agenda política dos países. Por outro lado, demonstra a articulação de instituições que unem esforços para fazer valer seus interesses e prioridades.

A FGV é uma instituição com forte atuação na área da administração, tanto em nível de graduação quanto de pós-graduação, e oferece cursos em diferentes estados e regiões do país. Além disso, conta com equipes de pesquisadores e consultores que se debruçam sobre a investigação de temas em variadas áreas do conhecimento.

$\mathrm{O}$ atendimento as demandas do mercado de trabalho é o enfoque privilegiado nos processos de formação promovidos pela instituição. A formação de líderes, o incentivo a valorização do mérito individual, o estímulo à concorrência (como pretensa estratégia de qualificação), são elementos que fundamentam os projetos e as ações da FGV. No item "visão" do Código de Ética e Conduta ${ }^{3}$ é descrito o que pretende a organização:

Ser reconhecida como instituição inovadora, comprometida com o desenvolvimento nacional, pela formação de uma elite acadêmica, pela geração de bens públicos nas áreas sociais e afins, e pela prestação de serviços com elevado padrão ético e de qualidade.

Ao registrar seu comprometimento com a formação de uma "elite acadêmica" evidencia um claro comprometimento com uma parcela muito restrita da população. Os valores institucionais da organização, também descritos no Código de Ética, merecem ser observados.

Valores Institucionais ${ }^{4}$. Trata-se de capturar o ideário nacional criando uma imagem multifacetada:

2 Os dados apresentados neste parágrafo foram extraídos de um vídeo, com duração de 6'46", sobre o evento, disponível o youtube: https://www.youtube.com/watch?v=t-6k9M-ylO4

3 Código aprovado pela Portaria n. 23/2017, da FGV. https://portal.fgv.br/sites/portal.fgv.br/files/codigo_etica_conduta_fgv_vf_2017.pdf

4 Esse é o título do tópico. 
- é uma instituição com tradição de seriedade e competência com mais de 70 anos de soluções;

- é inovadora e dinâmica;

- é uma instituição apartidária, mas com uma forte ideologia do interesse nacional;

- valoriza a diferenciação pelo mérito;

- tecnicamente procurará ser a melhor em todas as áreas que atua.

Ao indicar a diferenciação por mérito, como um valor institucional, a FGV assume o compromisso com uma forma de produzir conhecimento e ensinar, alicerçada na apreciação do esforço de cada um. A diferenciação por mérito, seja de um indivíduo ou de um grupo, é obtida a partir do reconhecimento de uma ação ou de um comportamento digno de distinção. Disso pode ou não resultar uma recompensa ou uma punição.

Aliado a ideia de "ser a melhor em todas as áreas que atua", o mérito assenta a FGV como uma organização que valoriza a concorrência, premissa elementar do mundo empresarial. São valores que dizem muito sobre uma instituição de ensino, pois fundamentam os planos, compromissos e as parcerias que serão firmados para a consecução de seus objetivos, em prol de um determinado projeto de sociedade.

$\mathrm{Na}$ apresentação dos think tanks, identificados com a lógica pró-mercado, a independência em relação a governos e partidos políticos sobressai-se como característica que é declarada por essas organizações. Esse é, no caso da FGV, um valor institucional: "é uma instituição apartidária, mas com uma forte ideologia do interesse nacional".

O fato de não desejarem o atrelamento a governos e partidos reflete o intuito de não circunscrever suas ações e projetos ao período de duração dos mandatos. Por outro lado, ao não estarem vinculadas a um ou outro partido, ficam menos sujeitas a aceitação ou rejeição do cidadão. Assim, podem penetrar na gestão dos serviços públicos, capilarizar a inserção de seus quadros, nas mais diversas áreas de atuação, e fazer valer sua forma de operar, impondo ao cidadão um tipo de gestão que, provavelmente, não foi prevista ou declarada no programa de nenhum partido.

Espaços e funções antes ocupadas por servidores públicos, com possibilidade de controle social do cidadão, agora são preenchidas por representantes que atuam para responder aos propósitos das organizações - que, por sua vez, prestam contas aos seus apoiadores e financiadores - não mais para a coisa pública. Declarações de redução da máquina estatal (corte de funcionários, CCs...), sob o pretexto de que esta é muito onerosa, na realidade encobrem gastos volumosos com essas organizações e a implementação de outras formas de gestão, menos afinadas com os princípios republicanos das instituições públicas de atendimento universal ${ }^{5}$.

Apresentam-se neutras, desprovidas de ideologia e, assim, podem fazer valer seus interesses extrapolando o tempo de gestão de um grupo eleito. Esse é um aspecto de

5 Exemplo dessa lógica foi a transferência de responsabilidade pela gestão dos hospitais universitários vinculados às Instituições Federais de Ensino, ao longo da segunda década do século XXI, para uma organização social, a Empresa Brasileira de Serviços Hospitalares (EBSERH). 
grande relevância, pois é uma forma de fazer política e de implementar ações, independentemente da vontade do cidadão. No não atrelamento (oficial) a partidos e governos evidencia-se um tipo de atuação que extrapola o tempo dos mandatos e cria-se a possibilidade de permanência em diferentes gestões, operando como verdadeiras agentes de Estado e não de governos.

O risco disso tudo é tornar tão natural para o cidadão esse tipo de penetração, a ponto de não causar estranhamento a condução privada da coisa pública e a ausência de qualquer tipo de controle sobre recursos materiais e humanos, projetos, parcerias, enfim, eliminar a possibilidade de fiscalização sobre aquilo que pertence a coletividade e interessa ao conjunto da sociedade.

a questão crucial, sob o domínio do capital, é assegurar que cada indivíduo adote como suas próprias as metas de reprodução objetivamente possíveis do sistema [...] no sentido verdadeiramente amplo do termo educação, trata-se de uma questão de "internalização" pelos indivíduos [...] da legitimidade da posição que Ihes foi atribuída na hierarquia social, juntamente com suas expectativas 'adequadas' e as formas de conduta 'certas', mais ou menos explicitamente estipuladas nesse terreno.[...] uma das funções principais da educação formal nas nossas sociedades é produzir tanta conformidade ou "consenso" quanto for capaz, a partir de dentro e por meio dos próprios limites institucionalizados e legalmente sancionados (MÉSZAROS, 2005, p. 44-45).

Além do discurso da independência em relação a partidos e governos, outra ideia recorrente é a da ausência de ideologia e da neutralidade de pensamento, nos documentos dos think tanks pró-mercado. É como se, naturalmente, assumir uma postura pró-mercado fosse algo normal e inquestionável. Ao analisar a realidade estadunidense Ravitch (2011) demonstra que o propósito dos think tanks é incubar em gerações de jornalistas e acadêmicos as ideias pró-mercado. São valores que vão sendo internalizados pelos sujeitos, ao longo de sua existência, de modo a parecer não haver outra forma de se relacionar com o mundo, dada a inevitabilidade da lógica do capital nas relações humanas (MÉSZAROS, 2005).

A penetração nas mais diversas áreas, com a produção e interpretação de dados de naturezas diversas, serve de referência para formar a opinião pública. Isso pode ser percebido na composição de pequenos grupos que são convidados para fazer a análise de temas econômicos, sociais, ambientais, educacionais, ou mesmo, conceder entrevistas sobre essas questões nos canais fechados ou mesmo nos canais abertos de largo alcance na sociedade.

Isso se expressa, inclusive, na produção científica em que, dado o aumento dessa participação privada na área educacional, é possível notar uma ampliação das investigações sobre o impacto dessas relações. Em um estudo sobre a produção em periódicos da Europa e da América do Norte sobre a internacionalização da educação superior, Morosini 
(2006) identifica como ponto chave dessa produção, a existência de um significativo número de trabalhos vinculados a grupos privados, "necessariamente não institucionais universitários" (p. 115). Ou seja, é uma realidade, já identificada na primeira década do século XXI, que, por um lado, faz pressão sobre a produção acadêmica, e por outro, revela tendências que vão sendo incorporadas aos sistemas educacionais.

\section{OS PROPÓSITOS DO CEIPEIFGV}

No ano de 2016 foi criado e em janeiro de 2017 iniciou a operar o Ceipe, definido como primeiro think tank brasileiro especializado em política educacional. A criação de um centro para atuar especificamente com política educacional é algo que merece uma atenção muito especial, tendo em vista o peculiar caráter da FGV de voltar-se para o atendimento das demandas do mercado. Entender o que pretende o centro, como se constitui e com quem se articula pode permitir um entendimento da natureza das pesquisas e das ações desenvolvidas por este braço da FGV, que tem como propósito auxiliar na elaboração das políticas educacionais, mas mais que isso:

O CEIPE tem como missão contribuir para que o Brasil tenha uma educação pública equitativa, inovadora e de qualidade por meio do apoio às Secretarias no desenho e implementação de políticas educacionais, da produção de conhecimento aplicado em políticas educacionais e da formação de líderes. (FGV, 2018)

A análise dos princípios e dos pressupostos da produção de pesquisas e materiais da FGV serve para revelar que tipo de consenso a instituição pretende criar na sociedade brasileira, em torno de um modelo de educação. A análise dos think tanks, neste momento específico do capitalismo, é relevante pelo seu crescimento e capilarização nas diferentes áreas e esferas governamentais, nas últimas décadas, conforme demonstrado na tabela 1.

Especificamente, na área educacional, essas organizações produzem materiais e pesquisas, organizam eventos, promovem formações, concedem entrevistas, participam de debates, orientadas por princípios que vão constituindo e formatando a gestão escolar, o trabalho docente e definindo um jeito de ser professor. Toda essa inserção no cotidiano social serve para produzir determinados ensinamentos sobre a educação no país e criar na população e, nos próprios trabalhadores em educação, expectativas sobre o que deve ser ensinado e valorizado pelas instituições educacionais.

Ao usarem os meios de comunicação, como é o caso da FGV, para replicar sua visão de educação, tornam rotineiros os discursos sobre determinados princípios que produzem ensinamentos às pessoas, que se educam a partir das oportunidades e dos acessos que têm. Ao não restringir a atuação ao interior das escolas ou das secretarias de educação e usar os meios de comunicação, buscam criar, na opinião pública, a simpatia pelos projetos que defendem e pelas parcerias que estabelecem, o que torna mais fácil a implementação 
de ações afinadas com os princípios do mercado na área educacional. Isso dificulta a resistência dos grupos que questionam essa lógica, em prol de outro projeto de educação, pois já há toda uma influência exercida na sociedade, sobre a inevitabilidade deste modelo e sobre o necessário atrelamento do trabalho na área educacional às demandas do capital.

Para legitimar suas ações o Ceipe utiliza a tradição da FGV, na produção de conhecimento aplicado, para definir sua atuação como um "centro de pesquisas, formação e assessoramento técnico para governos baseado em uma das mais prestigiosas escolas privadas do Brasil, a Escola Brasileira de Administração Pública e de Empresas da Fundação Getúlio Vargas" (CEIPE, 2018). De acordo com a descrição no site, o Ceipe pauta suas ações nos seguintes valores:

Equidade: Trabalhamos para garantir igualdade de oportunidades para todos os alunos brasileiros, independentemente do seu ponto de partida.

Excelência: Cultivamos uma cultura de altas expectativas e agimos com base em evidências científicas.

Inovação: Buscamos valorizar e desenvolver soluções criativas de forma que o aluno venha a ser participante pleno e protagonista em um mundo em rápida transformação.

Diversidade: Acreditamos que não existe um único caminho para garantir uma educação de qualidade e respeitamos e valorizamos os contextos e características locais.

Colaboração: Acreditamos que a mobilização e o engajamento da sociedade são fundamentais para a construção de uma educação de qualidade. Defendemos o regime de colaboração entre entes federados e a promoção da aprendizagem colaborativa nas salas de aula.

Formação Integral: Trabalhamos para que o aluno tenha autonomia e confiança para realizar o seu projeto de vida por meio de uma educação integral desde a Primeira Infância.

Entusiasmo: Somos apaixonados pela educação e acreditamos que ela seja o melhor meio para transformar o Brasil em um país justo, sustentável, efervescente e bom para se viver. (CEIPE, 2018)

Se, antes da criação do Ceipe, a FGV centrava mais a sua atuação em usuário da educação superior (graduação e pós-graduação), isto é, pessoas já na fase adulta; com um centro específico em política educacional, amplia esse atendimento para todas as fases de formação escolar, já sinalizando preocupação, inclusive, com a primeira infância, como pode ser visto em um dos valores preconizado pela instituição. A educação básica é, sem dúvida, o alvo da atenção do Centro.

As atividades do Ceipe estão concentradas em "três áreas de trabalho integradas e têm como objetivo a melhoria da educação básica brasileira” (CEIPE, 2018). São elas: 1. Apoio às redes públicas de ensino, 2. Produção de conhecimento aplicado; 3. Formação de líderes. O material disponibilizado pela organização tem como finalidade produzir conhecimento aplicado. 
O Ceipe conta com a parceria da Universidade de Harvard e o apoio do Instituto Brookings para seu funcionamento. O Instituto Brookings é, de acordo com o relatório da Universidade da Pensilvânia, o think tank mais influente do mundo, ocupando o primeiro lugar em um ranking produzido a partir da análise de 8.248 organizações no planeta.

É uma organização sem fins lucrativos, sediada em Washington, criada em 1916, que pretende buscar, por meio de estudos e pesquisas soluções para os problemas que afetam a sociedade. Apresenta-se como uma organização que foi pioneira, na esfera privada, no desenvolvimento de análises sobre políticas públicas em nível nacional (BROOKINGS, 2019). Declara-se como independente e sem posição sobre as questões que estuda. As pesquisas concentram-se na área de política externa, economia, desenvolvimento, governança e política interna. Na descrição dos programas de pesquisa, nessas áreas, a análise dos temas e as recomendações sobre os melhores caminhos a serem adotados, na definição das políticas, são centrais nas ações do Instituto, como pode ser percebido no trecho a seguir:

O programa Estudos de Governança, realizado em Brookings, é dedicado à análise de questões políticas, instituições e processos políticos e aos desafios contemporâneos da governança. Nossos experts identificam áreas que precisam de reforma e propõe soluções específicas com os objetivos de: melhorar o desempenho do governo nacional; debater informando; e fornecer aos formuladores de políticas análises e idéias especializadas para garantir uma melhor governança institucional ${ }^{6}$. (BROOKINGS, 2019 - tradução minha)

De acordo com o relatório anual do Instituto Brookings, no ano de 2018, a organização contou com recursos de 627 doadores, expostos no documento por valores designados. Os recursos provenientes de doações compõem $83 \%$ do orçamento anual da organização (BROOKINGS, 2018).Os 17\% restantes são compostos por dotação própria (11\%), publicações $(2 \%)$ e outros (4\%). No quadro a seguir são apresentados alguns desses doadores, localizados na sua devida faixa de concessão.

Quadro 1 - Doadores do Instituto Brookings, em 2018

\begin{tabular}{|l|r|l|}
\hline \multicolumn{1}{|c|}{ Faixa de Doação } & Número de doadores & \multicolumn{1}{c|}{ Doadores } \\
\hline$\$ 2,000,000$ e mais & 6 & $\begin{array}{l}\text { Bill \& Melinda Gates Foundation } \\
\text { Anne T. and Robert M. Bass }\end{array}$ \\
\hline $\begin{array}{l}\$ 1,000,000- \\
\$ 1,999,999\end{array}$ & $10 \begin{array}{l}\text { Laura and John Arnold Foundation } \\
\text { BHP Foundation }\end{array}$ \\
\hline
\end{tabular}

6 "The Governance Studies program at brookings is dedicated to analyzing policy issues, political institutions and processes, and contemporary governance challenges. Our scholarship identifies areas in need of reform and proposes specific solutions with the goals of: improving the performance of the national government; informing debate; and provinding policymakers with expert analysis and ideas to ensure better institucional governance". (BROOKINGS, 2019) 


\begin{tabular}{|l|r|l|}
\hline$\$ 500,000-\$ 999,999$ & 16 & $\begin{array}{l}\text { Ford Foundation } \\
\text { LEGO Foundation }\end{array}$ \\
\hline$\$ 250,000-\$ 499,999$ & 38 & $\begin{array}{l}\text { Bank of America } \\
\text { Microsoft Corporation } \\
\text { The Rockefeller Foundation }\end{array}$ \\
\hline$\$ 100,000-\$ 249,999$ & 32 & $\begin{array}{l}\text { Shell } \\
\text { Facebook } \\
\text { Hewlett-Packard Company } \\
\text { Omidyar Network } \\
\text { PepsiCo } \\
\text { Volvo Research and Educational Foundation }\end{array}$ \\
\hline$\$ 50,000-\$ 99,999$ & 88 & $\begin{array}{l}\text { Amazon.com } \\
\text { Intel Corporation } \\
\text { Visa Inc. }\end{array}$ \\
\hline$\$ 25,000-\$ 49,999$ & 67 & Airlines for America \\
\hline$\$ 10,000-\$ 24,999^{*}$ & 94 & \\
\hline$\$ 5,000-\$ 9,999^{*}$ & 40 & \\
\hline Menos de $\$ 4,999^{*}$ & 176 & \\
\hline
\end{tabular}

*nessas faixas de doação não há discriminação dos doadores

Fonte: Brookings Annual Report, 2018

A atuação dos think tanks não ocorre de forma isolada, mas junto com outras instituições e organizações. Há uma articulação entre parceiros, apoiadores e financiadores na execução e no planejamento das ações. Especificamente do Ceipe, são parceiros: Fundação Lemann, Instituto Unibanco, Instituto Natura, Itaú BBA, Omydiar Network, Itaú Social e Fundação Maria Cecília Vidigal. A constituição dos conselhos dessas instituições é reveladora da sua linha de atuação e dos direcionamentos das ações. No caso do Ceipe, compõem o Conselho: Fundação Lemann, Instituto Unibanco, Aondê Educacional, Todos pela Educação, Granenergia e Fundação Maria Cecília Souto Vidigal.

A percepção dessa articulação não serve apenas para mapear quem são os parceiros, como atuam e onde estão inseridos, mas para: a) ter a dimensão do trabalho dessas instituições na atualidade e a extensão da sua inserção na área governamental, pois ao se juntarem vão criado ramificações e expandindo seus princípios e interesses, consequentemente, ampliado sua área de atuação; b) compreender quais compromissos são assumidos por essas organizações e quais fundamentos defendem; c) conhecer as linhas de financiamento das ações desenvolvidas.

Possuímos uma visão ambiciosa: almejamos nos tornar um centro de referência nacional e internacional em políticas educacionais, contribuindo de forma significativa e duradoura para a melhoria da educação básica brasileira. (FGV, 2018)

Além dos parceiros declarados e aqueles que compõem o conselho da organização é possível encontrar outras organizações, no material publicado com apoio do Ceipe, que 
apoiam ou produzem de forma articulada projetos e materiais, como: Elos Educacional, Labi, Comunitas, Rede Juntos, Learning Policy Institute, Organização dos Estados Ibero-Americanos, AACS Accredited, entre outras.

A elaboração de materiais tem o propósito de produzir conhecimento aplicado, que possa ser largamente adotado em todos os níveis de ensino, afinal de acordo com a descrição dos propósitos do Ceipe: "temos como objetivo fomentar a produção de conhecimento aplicado em educação no Brasil, desenvolvendo materiais que atendam às demandas e interesses de gestores públicos, de formadores de opinião, da academia e da imprensa" (CEIPE, 2019).

Dizer às redes de ensino o que fazer para assegurar a qualidade da educação é o propósito do Ceipe. A organização pressupõe que seus consultores possuem as ferramentas para chegar em qualquer município do país e trabalhar com um rol de competências, junto aos gestores municipais, para o desenvolvimento das redes. Uma percepção simplista dos problemas que afligem a educação brasileira.

Qualquer mudança na educação pública passa por pessoas, principalmente aquelas que estão nas mais de 5.500 secretarias municipais e estaduais de educação do Brasil. Sem equipes técnicas qualificadas capazes de diagnosticar os problemas, pensar soluções e com capacidade de implementá-las, não teremos redes públicas de ensino de qualidade. Nossos projetos de Apoio às Redes, necessariamente contém um forte componente de qualificação das equipes com as quais trabalhamos para que possam dar continuidade ao trabalho após a saída dos nossos consultores. Um dos principais meios de apoio é a mentoria que oferecemos aos Secretários de Educação. Nossa metodologia parte de uma matriz de competências que todo gestor educacional deve dominar, identifica lacunas e oferece apoio neste desenvolvimento, permitindo que a/o Secretária/o se sinta mais capaz de promover a transformação da sua rede de ensino, garantindo inclusive a melhoria da aprendizagem dos seus alunos, de maneira efetiva e duradoura. (CEIPE, 2019)

Para demonstrar quais são as organizações parceiras do Ceipe na elaboração dos materiais foi estruturado um quadro com a exposição de um levantamento da produção disponibilizada no site da organização.

Quadro 2 - Parceiros do CEIPE na publicação de materiais

\begin{tabular}{|l|l|}
\hline \multicolumn{1}{|c|}{ Título da Produção } & \multicolumn{1}{|c|}{ Parceiro(s) } \\
\hline $\begin{array}{l}\text { Como melhorar o seu IDEB: experiências que } \\
\text { funcionam. }\end{array}$ & $\begin{array}{l}\text { Comunitas } \\
\text { Rede Juntos }\end{array}$ \\
\hline $\begin{array}{l}\text { Educação em pauta: uma agenda para a edu- } \\
\text { cação no país. }\end{array}$ & Organização dos Estados Ibero-Americanos \\
\hline
\end{tabular}




\begin{tabular}{|c|c|}
\hline $\begin{array}{l}\text { Millions Learning: ampliando a escala da edu- } \\
\text { cação de qualidade em países em desenvol- } \\
\text { vimento }\end{array}$ & $\begin{array}{l}\text { Instituto Brookings (Center for Universal Education at } \\
\text { Brookings) } \\
\text { LABI } \\
\text { Instituto Natura } \\
\text { Apoio para a pesquisa que sustentou o material: Cate- } \\
\text { rine T. Mac Arthur Foundation } \\
\text { Mastercard Foundation } \\
\text { Lego Foundation } \\
\text { Governo da Noruega } \\
\text { William e Flora Hewlett Foundation }\end{array}$ \\
\hline $\begin{array}{l}\text { Educação Já: cenário educacional no Rio de } \\
\text { Janeiro. }\end{array}$ & Todos pela Educação \\
\hline $\begin{array}{l}\text { Políticas públicas em ação, 1. Intervenções } \\
\text { baseadas em evidências: um guia para os es- } \\
\text { tados. }\end{array}$ & Learning Policy Institute \\
\hline $\begin{array}{l}\text { Políticas públicas em ação, } 2 \text {. Os ingredientes } \\
\text { dos programas de educação infantil de alta } \\
\text { qualidade. }\end{array}$ & Learning Policy Institute \\
\hline $\begin{array}{l}\text { Políticas públicas em ação, 3. Como tornar a } \\
\text { formação de professores efetiva. }\end{array}$ & Learning Policy Institute \\
\hline $\begin{array}{l}\text { Políticas públicas em ação, } 4 \text {. Escolas inte- } \\
\text { gradas: uma estratégia para um desenvolvi- } \\
\text { mento escolar de qualidade. }\end{array}$ & Learning Policy Institute \\
\hline $\begin{array}{l}\text { Bridges to the future of education: policy re- } \\
\text { commendations for the digital age. }\end{array}$ & \begin{tabular}{|l} 
G20 \\
Think Tanks \\
Centros de Pesquisa
\end{tabular} \\
\hline $\begin{array}{l}\text { Por uma nova formação continuada: diálogos, } \\
\text { experiências e a formação de professores do } \\
\text { século } 21 .\end{array}$ & $\begin{array}{l}\text { Tellus } \\
\text { LABI } \\
\text { Instituto Natura } \\
\text { Learning First } \\
\end{array}$ \\
\hline Aula nota 2.0. & $\begin{array}{l}\text { Fundação Lemann } \\
\text { Elos Educacional } \\
\text { Apoio para a produção do material: } \\
\text { Carnegie Foundation } \\
\text { Kern Family Foundation } \\
\text { Norman Atkins }\end{array}$ \\
\hline
\end{tabular}

Fonte: (www.ceipe.fgv)

Como é possível observar são muitas as parcerias estabelecidas pelo Ceipe para buscar a consecução de seus objetivos. Mesmo sendo uma organização com pouco tempo de criação, já consegue estabelecer parcerias com instituições de natureza variada: empresas, bancos, ongs, fundações. Essas parcerias criam as condições financeiras e operacionais para ampliar sua atuação em nível nacional e capilarizar seu trabalho.

Dos estudos dos materiais ${ }^{7}$ do Ceipe, neste texto, dois elementos são destacados para análise: a localização dos problemas educacionais na atuação dos professores e o privilégio do uso do conceito de liderança nas discussões sobre as questões da área.

7 Muitas análises podem ser depreendidas do material, mas a pesquisa exige que recortes sejam realizados para dar conta dos propósitos do estudo. 


\section{A RESPONSABILIZAÇÃO DOS PROFESSORES}

A responsabilização dos professores pelo sucesso do trabalho escolar se expressa em vários registros do Ceipe. O comprometimento com o trabalho é apontado como chave para o bom desempenho dos estudantes. Isso pode ser ilustrado com o evento promovido pelo think tank, no dia 6 de julho de 2019, com o tema: "Professores que transformam e a valorização docente", cujo objetivo era "refletir sobre a importância do papel do professor e de sua valorização no ensino público".

A presença destacada no evento é do queniano Peter Tabichi, eleito o melhor professor do mundo, vencedor do Global Teacher Prize 2019, prêmio concedido pela Fundação Varkey, uma organização não governamental britânica. O prêmio é largamente tratado nos meios de comunicação como um "Nobel" da Educação. O vencedor ganha destaque na imprensa internacional e recebe um prêmio de 1 milhão de dólares (FGV, 2020).

A realização de um evento focado na figura de Peter Tabichi e a exaltação do seu trabalho revelam o apreço e a simpatia do Ceipe por um tipo de professor e de atuação docente. O reconhecimento internacional do trabalho, que desencadeou o convite para participar do evento no Brasil, alimenta uma concepção de docência alicerçada na doação, na vocação e na generosidade. Um evento que pretende discutir a valorização do professor, ao alimentar essa percepção, reforça a ideia de uma docência desprofissionalizada.

\footnotetext{
O professor doa quase todo o seu salário", "[...] usou na cerimônia [de premiação] o hábito da Ordem de São Francisco de Assis, amarrado na cintura com um cordão franciscano de três nós para representar a pobreza, a castidade e a obediência"[...], "[...]o religioso começou a ensinar em uma instituição privada, mas logo se conscientizou de que fazia mais falta em uma comunidade menor. A chave para o seu sucesso acadêmico está no clube de ciências que ele criou, no qual incentiva as crianças a experimentarem, apesar dos recursos limitados". (SILIÓ, 2019)
}

A diretora do Ceipe, Claudia Costin, faz críticas ao trabalho e a formação dos professores no Brasil, em uma entrevista concedida a Monteiro (2018). A diretora foi Secretária Municipal de Educação do Rio de Janeiro, Secretária de Cultura do Estado do Rio de Janeiro, diretora sênior para educação no Banco Mundial. Ao avaliar a educação brasileira tece considerações sobre a qualidade do ensino no Brasil que, recorrentemente, convergem para a formação e atuação do professor. Não descarta outros condicionantes como relevantes para a melhoria da educação no país, como a existência de um programa nacional de alfabetização ou o investimento no ensino técnico, mas, nas seis páginas da referida entrevista, concentra suas críticas ao trabalho dos professores.

Essas críticas são apresentadas em diferentes momentos da entrevista, inseridas nos temas em discussão. Mesmo contrária a forma de realização da Reforma do Ensino Médio, por ter sido apresentado ao Congresso por medida provisória, Costin a considera 
uma boa ideia. Entende que há um exagero no número de disciplinas obrigatórias nesse nível de ensino e vê como algo positivo a adoção de itinerários formativos. Em duas passagens da entrevista, questiona o posicionamento dos professores brasileiros que defendem currículos com disciplinas obrigatórias, como pode ser visto nos seguintes trechos.

\begin{abstract}
Ninguém tem muita coragem de enfrentar as corporações de professores - quando falo isso, não me refiro nem aos sindicatos, mas às associações de professores. É curioso que, na época, todo mundo falou do impacto em artes, sociologia, mas ninguém mencionou química, física, biologia...

Nenhum país do mundo tem cem por cento de matérias obrigatórias, muito menos com o objetivo de atender à demanda dos professores. Professores são os principais atores, mas não a finalidade da política educacional. Alimentamos essas visões em educação por piedade e não devido a um foco na profissionalização do professor. E também pelo poder do lobby. (MONTEIRO, 2018, p. 15-16)
\end{abstract}

Suas análises sugerem que os professores ao defenderem a permanência das disciplinas o fazem para conservar seus empregos ${ }^{8}$, ou seja, adotam atitudes eminentemente corporativas. Na segunda passagem, parece ignorar que algumas áreas do conhecimento tiveram na história da educação brasileira grandes entraves para se consolidarem e, por essa razão, são alvo de mais acirradas manifestações dos trabalhadores em educação para serem inseridas nos currículos escolares.

Ao tratar das equipes diretivas das escolas públicas, percebe como "complicada" a eleição de diretores e entende haver que "falta uma abordagem profissional da indicação de diretores da escola" (MONTEIRO, 2018, p. 14). Mais uma vez, expressa desconfiança no trabalho dos professores ao afirmar,

a eleição pura e simples pode levar ao corporativismo e, se não se toma cuidado, favorece pactos corporativistas. $\mathrm{O}$ arranjo de diretor e professor não pegarem um no pé do outro, para manter as boas relações se amanhã o diretor voltar à sala de aula e aquele professor assumir a direção. (MONTEIRO, 2018, p. 14)

Ao argumentar sobre a pouca atratividade do trabalho docente para os jovens lembra dos salários e do "baixíssimo reconhecimento social da carreira", como entraves para essa escolha profissional.

E a imprensa muitas vezes cai na tentação de uma coisa que, na falta de um nome melhor, a gente poderia chamar de coitadização do professor, ao contar histórias abordando esse profissional sempre como um sofrido, com histórias de superação frente a péssimas condições de trabalho. Ninguém deseja ser uma coisa de quem as pessoas têm pena. (MONTEIRO, 2018, p. 14)

80 que seria legítimo também, pois qualquer trabalhador, na medida em que retira sua sobrevivência da venda da sua força de trabalho, lutará para manter as funções que desempenha. 
Aqui é preciso lembrar que não se trata de um comportamento adotado exclusivamente pela imprensa, já que a própria organização que Costin dirige contribui nessa "coitadização do professor", ao promover um evento, cujo destaque principal é justamente o trabalho de superação de um professor, que doa seu salário frente às péssimas condições de existência e de trabalho que dispõe em seu país. Isto é absolutamente contraditório, pois se o Ceipe pretende exercer influência na elaboração das políticas educacionais, ao promover um evento com essas características está se posicionando favoravelmente a esse tipo de ação.

Ao tratar do $\mathrm{Pisa}^{9}$, Costin demonstra preocupação com os resultados obtidos pelo Brasil e afirma que, na edição de 2015, o quesito em que os resultados foram piores foi "pensar utilizando conceitos científicos". Mais uma vez, os professores são responsabilizados na entrevista: "para mudar isso, é preciso formar melhor o professor. Tem que mudar a formação inicial, dar uma formação que integre melhor as várias disciplinas, e o eixo deveria ensinar a pensar". (MONTEIRO, 2018, p. 16)

Ao finalizar a entrevista elege algumas prioridades para a área educacional. Coerente com todo o conteúdo da entrevista, define como prioridade número um, o investimento na "profissionalização do professor". Sugere a

criação de uma avaliação nacional de professores - projeto que já existiu, quando Haddad foi ministro da Educação -, que pudesse servir para duas coisas: ter uma certificação nacional; elou servir como etapa para baratear o processo, ser um tipo de Sistema de Seleção Unificada (Sisu) dos professores. (MONTEIRO, 2018, p. 17)

É interessante registrar que o financiamento é o último elemento mencionado nas prioridades educacionais da diretora do Ceipe, cuja menção reduz-se a seguinte declaração: "e ter consciência da questão do financiamento, que terá que aumentar, de forma mais eficiente" (MONTEIRO, 2018, p. 17) Ao introduzir a entrevista e apresentar Claudia Costin, Monteiro (2018) descreve: "[...] defendeu que, sem uma revisão na forma de ensinar os alunos e de formar professores, não haverá lei ou orçamento que nos resgate desse atraso". (MONTEIRO, 2018, p. 15)

O desenvolvimento de competências socioemocionais também foi mencionado pela entrevistada como imprescindível à formação dos jovens, em especial para os oriundos das camadas mais desfavorecidas economicamente:

[...] você tem que ensinar competências socioemocionais, quesito em que estamos mal. É uma competência fundamental para o século XXI, e é uma competência fundamental para qualquer jovem de origem vulnerável para superar suas dificuldades, que Ihe concede persistência, garra, resiliência. (MONTEIRO, 2018, p. 17)

9 É um Programa Internacional de Avaliação de Alunos, iniciado em 2000, coordenado pela Organização para a Cooperação e Desenvolvimento Econômico (OCDE). 


\section{O PRINCÍPIO DA LIDERANÇA NAS UNIDADES ESCOLARES}

Não há barreiras legais para impedir as parcerias. Ao contrário, pois se nas redes públicas os investimentos são limitados por legislações que restringem a sua aplicação e qualificação, "no caso da lei de responsabilidade fiscal, ela impede a contratação de pessoal (professores, por exemplo), mas libera a contratação de empresas terceirizadas" (FREITAS, 2018, p. 79). São criadas, dessa forma, as condições para o crescimento das organizações privadas na educação e a fragilização do público estatal.

A forma de atuação dos think tanks pró-mercado precisa ser amplamente discutida e debatida na academia. Não apenas porque são financiados por grandes corporações, interessadas em ampliar suas taxas de lucro, mas porque têm promovido a destruição de uma concepção de educação pública, voltada para os interesses da classe trabalhadora. Como afirma Freitas (2018, p. 35) "entender [...] os meios de destruição da escola pública que são postos em marcha é fundamental para que se possa organizar a resistência".

$\mathrm{Na}$ análise do material da FGV e, mais especificamente do Ceipe, o conceito de liderança destaca-se como determinante das ações da organização, como princípio que pauta os processos de formação. Inclusive, na descrição do material produzido, destaque é conferido à formação de lideranças.

Nunca esteve no horizonte dos princípios de uma educação democrática a formação de líderes, mas a formação de sujeitos, que, por buscarem os mesmos propósitos, teriam a possibilidade de participar diretamente da definição e dos rumos dos processos formativos. Esse é um entendimento de que os integrantes da comunidade escolar, em qualquer nível de ensino, ocupam funções diferentes. Porém, essas posições não os colocam em posição de superioridade ou inferioridade em relação a outras. Trabalha-se um tipo de relação horizontalizada, cuja participação e coletividade constituem-se elementos essenciais para a formação de todos os envolvidos.

A meritocracia e o empreendedorismo passam a dominar o sistema educacional, seja pela adoção indiscriminada das avaliações em larga escala no país ou pela transferência das formas de gestão do mercado para a área educacional. O mérito é tratado totalmente desconectado da condição de existência do indivíduo, produto daquilo que a sociedade historicamente construiu. Nessa lógica, não há espaço para o questionamento do "mérito" da transmissão de bens e patrimônio, por meio da herança de grandes fortunas, e do acúmulo de riqueza por uma pequena parcela da população, graças ao esforço do trabalho explorado da maior parte dos trabalhadores.

Antes de considerar os objetivos e atividades específicas dessas fundações, vale a pena refletir sobre a sabedoria envolvida em permitir que as políticas de educação sejam direcionadas ou, poder-se-ia dizer, capturadas pelas fundações privadas. Há algo de fundamentalmente antidemocrático em entregar o controle das políticas para a educação pública para fundações privadas comandadas pelas pessoas 
mais ricas da sociedade; quando as mais ricas dessas fundações se juntam por um propósito comum, elas representam uma força particularmente poderosa que está além do alcance das instituições democráticas. Essas fundações, não importa quão válidas e bem intencionadas, não são organizações públicas. Elas não são sujeitas a supervisão ou revisão do público, como uma organização pública seria. (RAVIT$\mathrm{CH}, 2011$, p. 224-225)

Tais organizações não defendem a privatização direta (RIKOWSKI, 2019) das instituições educacionais, que continuam pertencendo ao Estado, mas pretendem fazê-lo funcionar sob a lógica do mercado, submetendo o interesse público aos valores do capital. No caso das instituições educacionais são decisões que interferem na vida de todos, mas que são tomadas por pequenos grupos, sem a possibilidade de controle social.

Interessa aos grupos dominantes que nos preocupemos com rankings e classificações por duas razões. Primeiro, para reforçar a ideia de que o esforço e a meritocracia devem ser premiados e reconhecidos e segundo, infinitamente mais grave, para alicerçar um sistema educacional no treinamento para testes e provas e não em uma real apropriação daquilo que uma instituição educativa pode oferecer.

Quanto mais profundo o conhecimento da realidade, mais críticas e questionamentos poderão ser construídos nas relações pedagógicas. Docentes e estudantes ampliam seus argumentos e aprofundam seus conhecimentos com a divergência de ideias e com a valorização do pensamento crítico. Isso significa pensar em uma educação que opera na lógica do desenvolvimento do pensamento autônomo, de formação de sujeitos, que não se conformam facilmente, mas duvidam, questionam, debatem.

\section{CONCLUSÃO}

Não é por acaso que uma organização com tradição no país na área da administração crie um think tank específico para atuar com política educacional. É inevitável a influência que um trabalhador em educação, em especial o docente, exerce na vida de uma pessoa, dado o longo e sistemático tempo de permanência na escola de todos os sujeitos, desde os primeiros anos de vida.

Conceitos elaborados e debatidos a partir de uma perspectiva transformadora da educação, são utilizados com a intenção de fomentar um projeto neoliberal. Quando não há uma clareza em relação à perspectiva epistemológica, que sustenta o uso de determinado conceito, que permita uma crítica ao uso distorcido do termo, pode haver uma confusão conceitual. Como se um termo pudesse se explicar por si só. Com uma "ilusória" adoção dos valores progressistas esses projetos adentram com maior facilidade nas redes e unidades de ensino, já que "aparentemente" respondem aos anseios e necessidades históricas dos trabalhadores em educação.

Aquilo que, em um primeiro momento, causa estranhamento aos sujeitos que participam diretamente das atividades educacionais, como a defesa da liderança e do em- 
preendedorismo na educação, de tanto serem repetidos e propagados vão sendo aceitos e incorporados aos debates, adentrando de forma sutil, mas naturalizando a introdução de determinados valores e conceitos que passam a ser tratados como se fizessem parte das prioridades na área. Ao se incorporarem ao cotidiano escolar deixam de causar estranhamento e são alvo de menores críticas e questionamentos dos trabalhadores em educação, que passam a inserir essas premissas no trabalho escolar.

Os think tanks atuam para dar o direcionamento das políticas, sem, entretanto, ocupar funções diretamente dentro das secretarias de educação, pois atuam por meio de assessorias, consultorias e parcerias. Ao buscar exercer toda essa influência na opinião pública um think tank age como verdadeiro produtor de determinados padrões de inserção na vida social.

Essas organizações, além de exercerem influência nos atos governamentais, fornecem força de trabalho para ocupar postos importantes no executivo em diferentes níveis de governo. O deslocamento de vários membros do Instituto Millenium, após a eleição de Jair Bolsonaro para a presidência da república do Brasil, em 2018, para ocupar postos no alto escalão do Ministério da Economia, ilustra essa situação. A realidade tem revelado que a experiência acumulada, por profissionais de diferentes áreas no interior dos think tanks, serve de trampolim para o preenchimento de vagas em funções estratégicas em diferentes níveis de governo. Mais uma razão para um olhar atento para essas organizações. 


\section{REFERÊNCIAS}

CARVALHO, Luis Miguel. Estudos analíticos sobre políticas educativas: um ensaio a partir da investigação doutoral realizada em Portugal. Educ. Soc., Campinas, v.26, n. 133, p. 1023-1040, out-dez, 2015.

CEIPE promove debate com Peter Tabichi sobre valorização professor. 2019. Disponível em: https:// ebape.fgv.br/noticias/ceipe-promove-debate-com-peter-tabichi-sobre-valorizacao-professor. Acesso em: 30 jan. 2020.

FREITAS, Luiz Carlos de. A reforma empresarial na educação. São Paulo: Expressão Popular, 2018.

FUNDAÇÃO GETULIO VARGAS. Centro de Excelência e Inovação em Políticas Educacionais. Disponível em: https://ceipe.fgv.br/. Acesso em: 15 jul. 2019.

HARVEY, David. O neoliberalismo: história e implicações. Rio de Janeiro: Loyola, 2008.

MÉSZAROS, Istvan. A educação para além do capital. São Paulo: Boitempo, 2005.

MONTEIRO, Solange. A escola brasileira não ensina a pensar: entrevista Claudia Costin. Revista Conjuntura Econômica, p. 12-17, 2018.

RACHEWSKI, Roberto. A educação pública estatal escraviza. 20 nov. 2018. Disponível em: https:// www.institutomillenium.org.br/a-educacao-publica-estatal-escraviza/. Acesso em: 20 mai. 2019.

RAVITCH, Diane. Vida e morte do grande sistema escolar norte americano: como os testes padronizados e o modelo de mercado ameaçam à educação. Porto Alegre: Sulina, 2011.

RIKOWSKI, Glenn. Privatização em educação e formas de mercadoria. Retratos da Escola. Brasília, v. 11, n. 21, p. 393-413, p. 393-413, 2017. Disponível em: https://www.esforce. org.br. Acesso em: 3 mai. 2019.

SILIÓ, Elisa. O melhor professor de 2019 é franciscano e tem um clube de ciências na parte mais remota do Quênia. El país. 25 de março de 2019. Disponível em: https://brasil.elpais.com/brasil/2019/03/24/actualidad/1553430035_587639.html Acesso em: 10 out. 2019.

UNIVERSITY OF PENSYLVANIA. 2018, Global Go To Think Tank Index Report. Disponível em: https://repository.upenn.edu/cgi/viewcontent.cgi?article=1017\&context=think_tanks> Acesso em: 15 dez. 2018.

\section{Sites consultados:}

www.brookings.edu

www.ceipe.fgv.br

www.heritage.org

www.portalfgv.br

www.renova.org

www.ted.com 